\title{
Hydration Heat in a Mass Concrete and a Thin Slab with Limestone Blended Cement
}

\author{
Mohammad Tahersima ${ }^{1 *}$, Tyler Ley², Paul Tikalsky ${ }^{3}$ \\ 1315 Advanced Technology Research Center, Stillwater, OK, USA. \\ 2 319C Engineering South, Stillwater, OK, USA. \\ ${ }^{3} 201$ Advanced Technology Research Center, Stillwater, OK, USA. \\ * Corresponding author. Tel.: 4055354159; email: mohammad.tahersima@okstate.edu \\ Manuscript submitted March 10, 2017; accepted April 24, 2017. \\ doi: 10.17706/ijmse.2017.5.2.79-86
}

\begin{abstract}
Concrete containing limestone blended cement or blended cement with limestone and fly ash have noticeably different thermal properties. Maximum temperature rise due to cement hydration plays an important role on delayed ettringite formation and thermal cracking of the concrete. However, the maximum temperature rise due to cement hydration in the mass concrete floor would be different from thin slabs. The purpose of this study is to provide such difference for concrete with limestone blended cement and fly ash type $\mathrm{C}$. In this study, results of thermocouple measurement at a new construction laboratory are compared via a $1.22 \mathrm{~m}$ thick mass concrete floor and a $0.18 \mathrm{~m}$ thin slab at the edge and center point of the foundation. The mass floor includes the virtical steel anchors which conduct the generated hydration heat to the bottom and surface of the slab. The results show that hydration heat is accumulated at the middle of the mass floor. Also, temperature profile of the thin slab and bottom heat flux records mostly follow the ambient temperature. In addition, the bottom of the mass floor is affected by hydration heat conducted by vertical steel.
\end{abstract}

Keywords: Thermal monitoring, limestone blended cement, cement hydration, mass concrete, thin floor

\section{Introduction}

Concrete is the second most common used material in the world [1]. It has many useful properties including durability, sustainability, availability, and economy. The initial hydration reactions of cement are exothermic and generate heat. The relatively low thermal conductivity of concrete can cause a thermal gap between the concrete and the ambient temperature [2]. Oftentimes, these differences in temperature can be quite large and lead to cracking of the concrete as the outer portions of mass concrete cool while interior portions of mass concrete remain heated. Concrete with limestone blended cement leads to carbon footprint reduction and lowers the energy needed to manufacture each ton of cement.

Thermal properties of concrete have been extensively studied for the design of mass concrete structures as well as for cracking and development considerations. The exothermic reaction in cement hydration may cause early age strain differentials in concrete contributing to cracking or displacement. While most types of individual cements have different heats of hydration due to their chemical composition, the recent rise in limestone blended cement as sustainable building material requires a wider investigation for benefits and design parameters. Limestone cement may have a better performce secondary cementitious material (SCM) in terms of durability. Bentz et al. stated that concretes with water to cement ratio more than 0.4 and limestone replacement will have higher diffusion rate [3]. Gurney et al. showed that using limestone cement 
can result in set acceleration that can alleviate the retarding effects of SCM replacement [4].

Cement is the main parameter in heat generation of concrete sections. There are some different types of cements which have different properties. They have been applied for various purposes. There are lots of mass concrete structure projects that the temperature control is an important key to avoid or minimize cracks [5]. Limestone blended cement is one of the noticeably versatile cements during the 21st century. Lower carbon dioxide production and inert filler properties of limestone are the accepted justifications for its usage. Therefore, it is necessary to investigate the heat of hydration by limestone blended cement. Rahal V.F et al. studied the influence of compositional and process variables on the early age hydration of limestone blended cement [6]. They concluded that limestone filler reduces the heat due to dilution effect. Lothenbach, B. et al. stated that limestone will accelerate the initial hydration reaction and affect assemblage of the hydrating cement pastes [7].

A supplementary cementitious material (SCM) is a material used in combination with portland cement, contributes to the properties of the hardened concrete through hydraulic or pozzolanic activity or both. The microstructure of cement matrix and durability of concrete are improved because of their pozzolanic effect and physical properties [8]. Fly ash is one of SCMs which is a result of the combustion of pulverized coal. Type C (high calcium) and type F (low calcium) are two most common types of fly ash. The addition of fly ash further reduces the mass of blended cement needed per cubic yard of concrete, reducing the energy density of the overall concrete [9].

Mass concrete is any volume of concrete with dimensions large enough to require measures to be taken to overcome heat generation from cement hydration, by reducing the volume change in order to minimize cracking [10]. Typically mass concrete is referred to as any structure with any dimension of greater than $1.5 \mathrm{~m}$. Making mass concrete involves use of a high cement percentage. Thick slabs can store more heat of cement hydration due to the low thermal conductivity of concrete.

Some research has been conducted on the subsequent effects of temperature rise in mass concrete construction [11]-[13]. If the peak temperature rise exceeds the maximum allowable temperature of the concrete structures, some further consideration should be regarded including pre or post cooling of concrete section. The purpose of this article is to investigate the thermal monitoring of the concrete with blended limestone cement after placing the concrete. The comparison between cement hydration in mass of concrete and thin slab is studied.

\section{Experiments}

The experimental platform for this research was coordinated with the new construction Laboratory at Oklahoma State University. This building was constructed between 2014-2015 with a mass concrete structural load floor and large areas for fabrication, offices and training. The building is over $3000 \mathrm{~m} 2$ area.

A $1.22 \mathrm{~m}$ thick mass concrete floor with $36 \times 14 \mathrm{~m} 2$ surface area was placed on $7.5 \mathrm{~cm}$ mud slab in the center of the laboratory. This slab has a heating tube system which is located $15 \mathrm{~cm}$ below the surface to provide heating and cooling comfort for the lab. The mass concrete floor includes the vertical steel, and top and bottom mesh. The reinforcement detail of the $1.22 \mathrm{~m}$ mass floor is shown in Fig. 1. The spacing interval of all steel anchor is $1.22 \mathrm{~m}$ on-center and the diameter of each vertical steel anchor is $3.81 \mathrm{~cm}$. Also, $0.18 \mathrm{~m}$ slabs were cast in the fabrication areas; these were placed on $2.5 \mathrm{~cm}$ polystyrene insulation.

To study the thermal behavior of concrete floor, concrete mixture proportions need to be recognized. The main factor of generated heat by cement hydration is paste composed of cement, SCM, and water. The mixture proportion design of the concrete slab is presented in Table 1. 


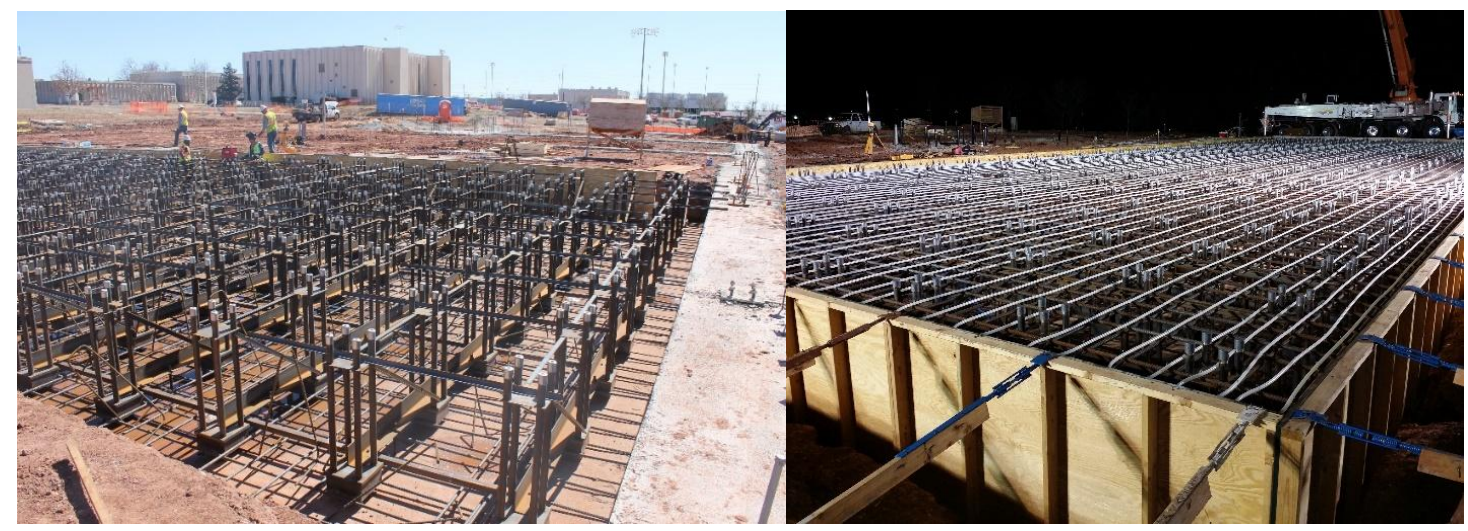

Fig. 1. Reinforcing detail in the mass floor.

Table 1. Mix Design of the Site

\begin{tabular}{cccc}
\hline Material Type & Design Quantity [kg] & Specific Gravity & Volume [m $\mathbf{m}^{\mathbf{3}}$ \\
\hline $\begin{array}{c}\text { Limstone Blended } \\
\text { Cement }\end{array}$ & 187.79 & 3.15 & 0.0597 \\
Type C Fly Ash & 46.72 & 2.65 & 0.0175 \\
Water & 115.46 & 1.00 & 0.115 \\
Coarse Agg \#57 & 784.71 & 2.80 & 0.2803 \\
Coarse Agg \#2 & 188.24 & 2.80 & 0.0674 \\
Fine Agg & 559.73 & 2.63 & 0.2129 \\
Water Reducer & $0.439 \quad$ lq & 1.00 & 0.01 \\
\hline
\end{tabular}

Based on Table 1 information, it can be found that site paste has limestone blended cement, Fly Ash plus water with 0.49 of water to cementitious material ratio. The aggregate is composed of natural sand as fine aggregate and limestone coarse aggregate. Also, It is necessary to look at the chemical composition of this type of limestone blended cement which is shown at Table 2. Limestone particles have filler properties. Greater densification of the cement paste improves the durability and strength of the sample [14].

Table 2. Chemical Composition of Holcim Cement IL [15]

\begin{tabular}{ccccccccc}
\hline Cement & $\begin{array}{c}\text { Blaine } \\
\left(\mathbf{m}^{2} / \mathbf{k g}\right)\end{array}$ & $\mathbf{- 3 2 5}$ & Limestone $\mathbf{\%}$ & $\mathbf{S i O}_{2}$ & $\mathbf{A l}_{2} \mathbf{O}_{3}$ & $\mathbf{F e}_{2} \mathbf{O}_{3}$ & $\mathbf{C a O}$ & $\mathbf{M g O}$ \\
\hline Type IL & 431 & 97.15 & 9.43 & 19.32 & 5.27 & 3.26 & 63.57 & 2.21 \\
& $\mathbf{N a}_{2} \mathbf{O}$ & $\mathbf{K}_{\mathbf{2}} \mathbf{O}$ & $\mathbf{S O}_{3}$ & $\mathbf{C}_{3} \mathbf{S}$ & $\mathbf{C}_{\mathbf{2}} \mathbf{S}$ & $\mathbf{C}_{3} \mathbf{A}$ & $\mathbf{C}_{\mathbf{4}} \mathbf{A F}$ & $\mathbf{N A}_{\mathrm{EQ}}$ \\
\hline & 0.14 & 0.59 & 2.97 & 49.78 & 16.37 & 8.54 & 9.65 & 0.53 \\
\hline
\end{tabular}

\section{Instrumentation}

Instrumentation at the site was completed by T-type thermocouples. Thermocouple wires were attached to a column of concrete to read the temperature at different elevations of slab depth before casting the concrete. The average of two thermocouple readings at each location is used for collecting the temperature data to verify the accuracy of the results. All thermocouple wires were connected to a data logger for measuring the temperature every 5 minutes. The thermocouples' position in the $1.22 \mathrm{~m}$ and $0.18 \mathrm{~m}$ floor is shown in Fig. 2 , Fig. 3 by triangular dots, respectively. Also, the heat flux sensor was placed at the bottom of thin slab to measure amount of heat delivered to the bottom of the thin slab. 


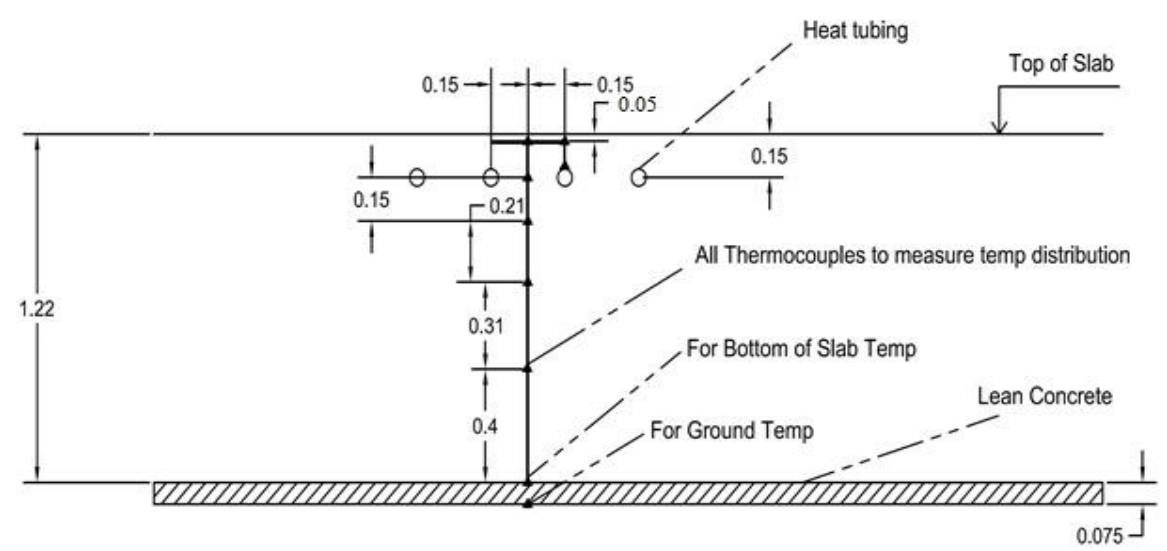

Fig. 2. Thermocouples location inside of $1.22 \mathrm{~m}$ thick slab (dimension is meter).

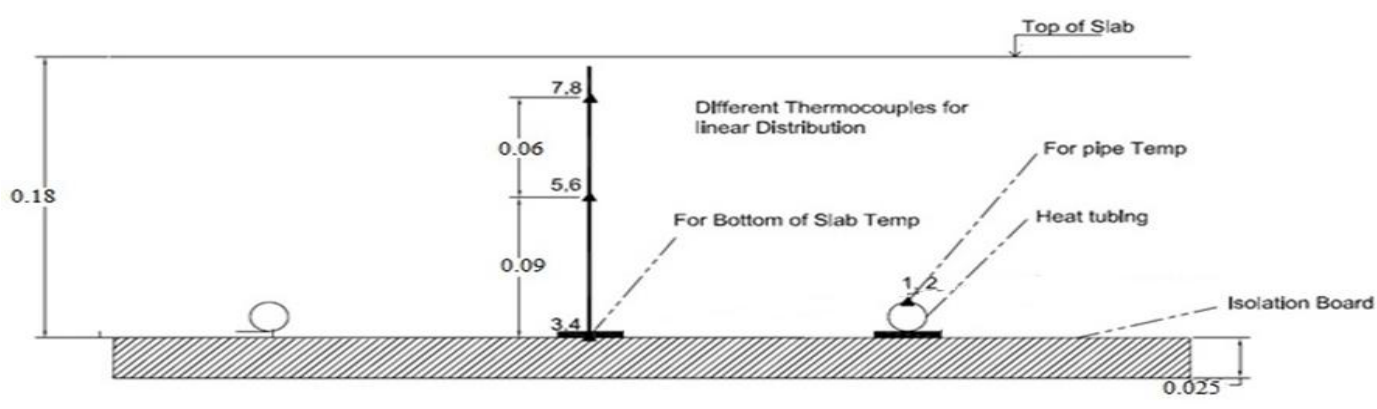

Fig. 3. Thermocouples location at $0.18 \mathrm{~m}$ slab (dimension is meter).

Every floor has two location of temperature measurement on the edge and center point of the slab. The edge point is located at $0.3 \mathrm{~m}$ from the edge of the building and the center point is located at $5 \mathrm{~m}$ from the edge of the building.

\section{Results and Discussion}

The temperature gradient in the mass concrete floor at three different elevations including $0.05 \mathrm{~m}$ ( 2 inches) below the surface, the middle point and the bottom of the slab (on the mud slab), and ambient temperature are presented in Fig. 4 and Fig. 5 over 1000 hours for the center and edge point.

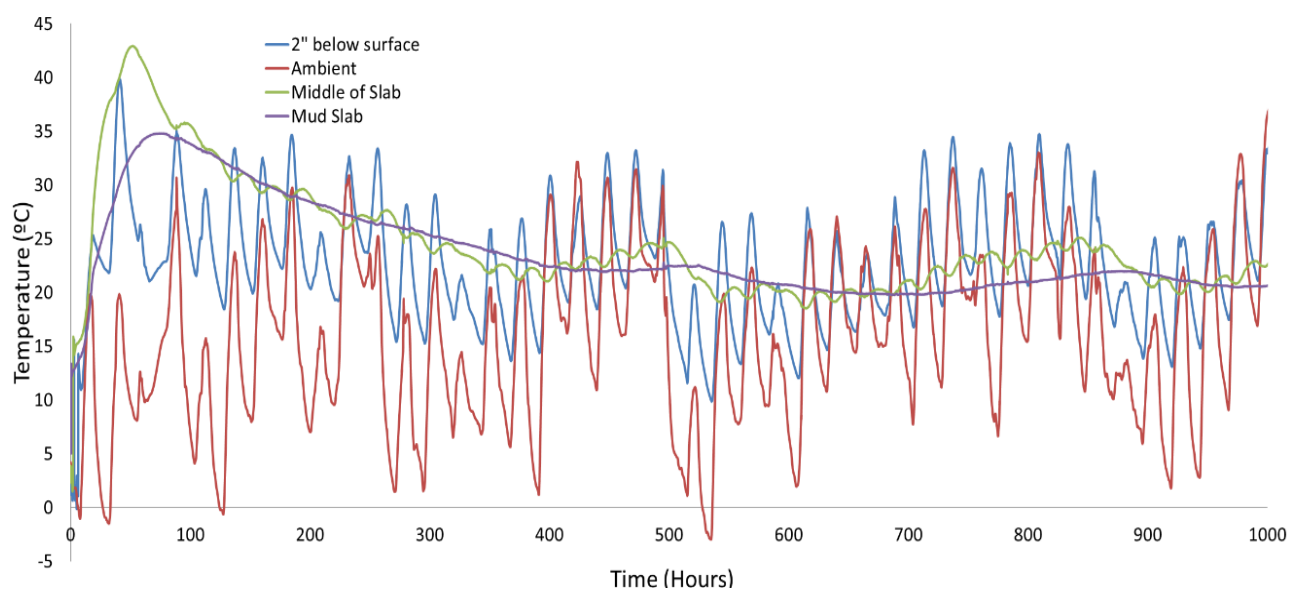

Fig. 4. Thermal gradient after casting the mass concrete (center point). 


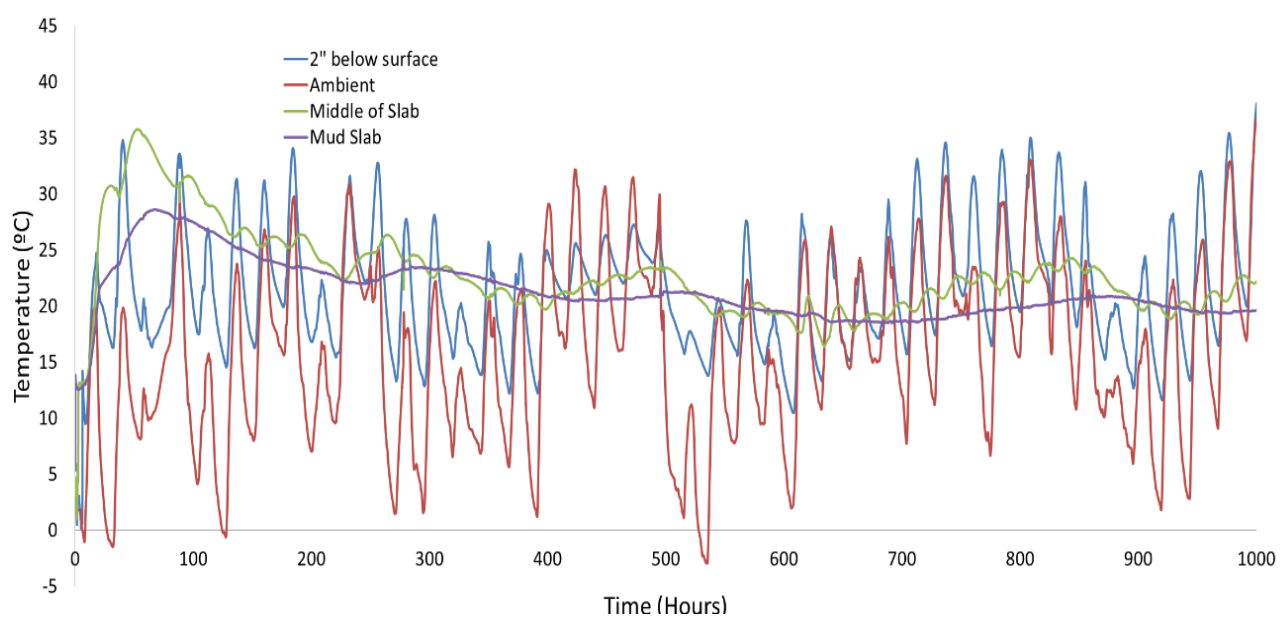

Fig. 5. Thermal gradient after casting the mass concrete (edge point).

The maximum temperature at the middle of the mass floor is $42.9^{\circ} \mathrm{C}\left(109.22^{\circ} \mathrm{F}\right)$ after 51.75 hours of casting the concrete for the center point and $35.31^{\circ} \mathrm{C}\left(96.8^{\circ} \mathrm{F}\right)$ after 56.83 hours for the edge point. The temperature trend is not fully followed by the ambient temperature at a deeper distance from the surface of the slab. For instance, $0.05 \mathrm{~m}$ ( 2 inches) below the surface is more affected by ambient temperature fluctuation. By increasing or decreasing the ambient temperature, the temperature of $0.05 \mathrm{~m}$ ( 2 inches) below the surface will be increased or decreased. However, the middle of the slab or mud slab temperature is increased because of temperature rise of cement hydration regardless of ambient temperature fluctuation. Therefore, the surface of the slab is more affected by ambient temperature rather than cement hydration influence. After the hydration peak, the thermal gradient of the middle and mud slab points are fluctuating due to the ambient temperature.

The difference between maximum temperature reached in the middle of slab for the edge and center point is $7.17^{\circ} \mathrm{C}$. At about 500 hours, the effects of heat of hydration is disappeared. As mentioned before, the thermal behavior of the thin slab regarding the cement hydration is different from the mass concrete floor.

The temperature rise in the center point and edge point of the slab would be different because the heat could be stored in the center of the slab. This thermal behavior of ground point is shown in Fig. 6 for the under the mud slab temperature.

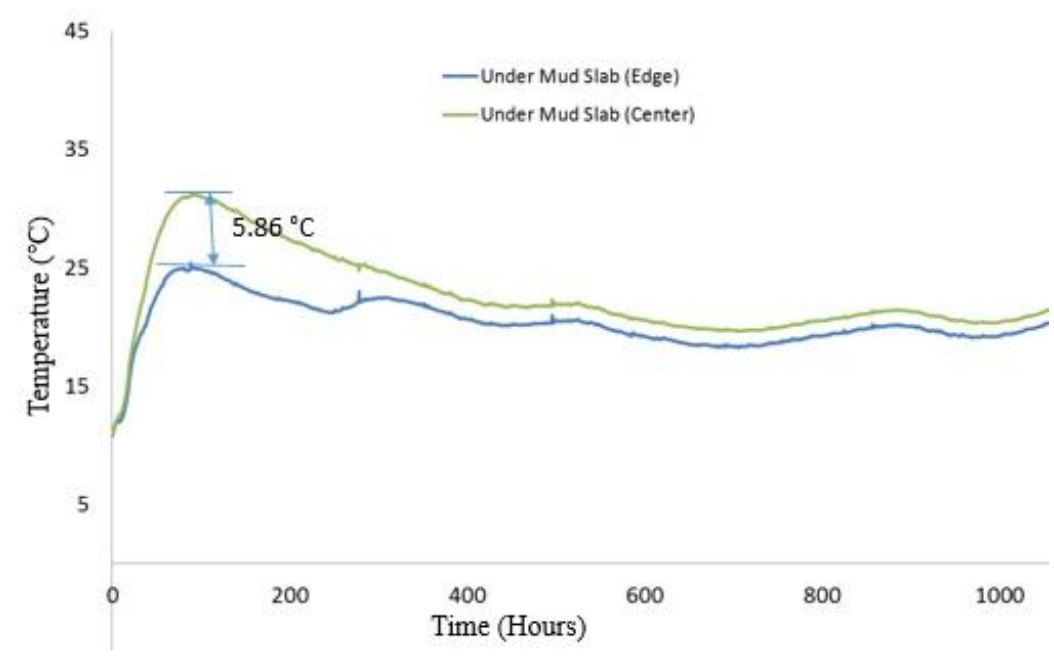

Fig. 6. Temperature profile at the under mass floor for edge and center point. 
Fig. 6 indicates that the ground (under the mud slab) temperature is also affected the generated heay by cement hydration. The vertical steel anchors are responsible for conducting heat to the bottom of slab because of considerably higher thermal conductivity than concrete. The difference between maximum temperature reached in the middle of slab for the ground point is $5.86^{\circ} \mathrm{C}$. It means the heat accumulation in the middle of slab would be in a higher rate than the ground point.

The temperature profile inside of thin slab for the center point is shown in Fig. 7.

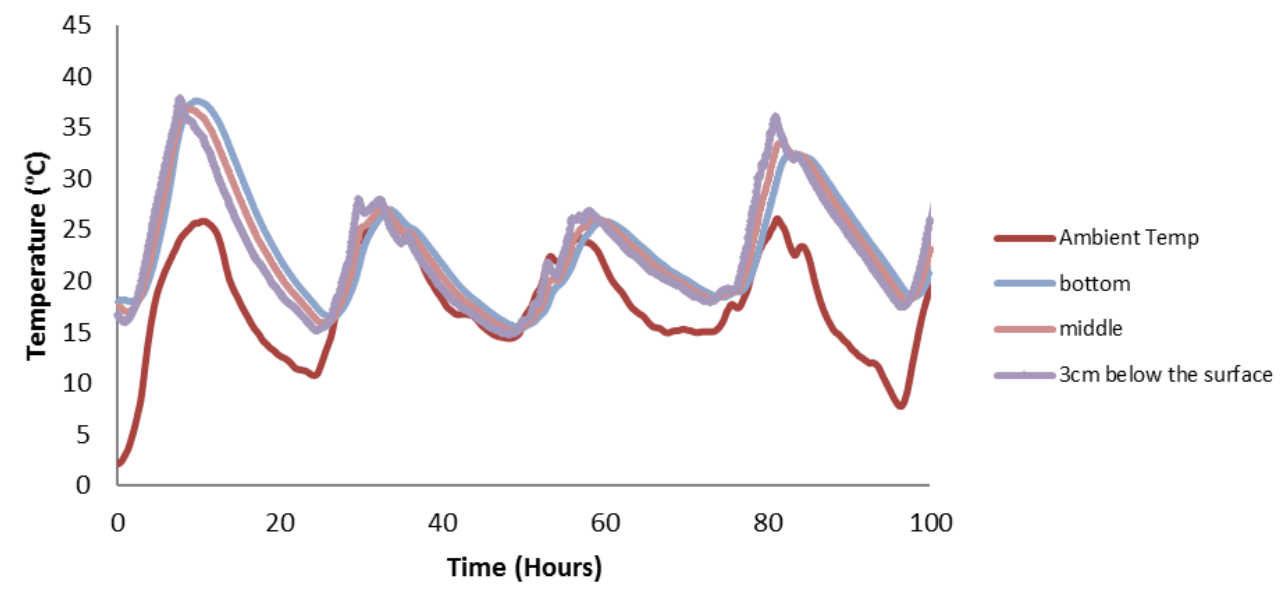

Fig. 7. Thermal gradient after casting the thin concrete slab (center point).

Due to the thinness of the $0.18 \mathrm{~m}$ concrete slab, most of the heat of hydration can escape through the top of the slab because the bottom and all around the edges of thin slab is surrounded by $2.5 \mathrm{~cm}$ thermal insulation. Heat flux measurement at the bottom of the thin slab for the center and edge point is presented in Fig. 8.

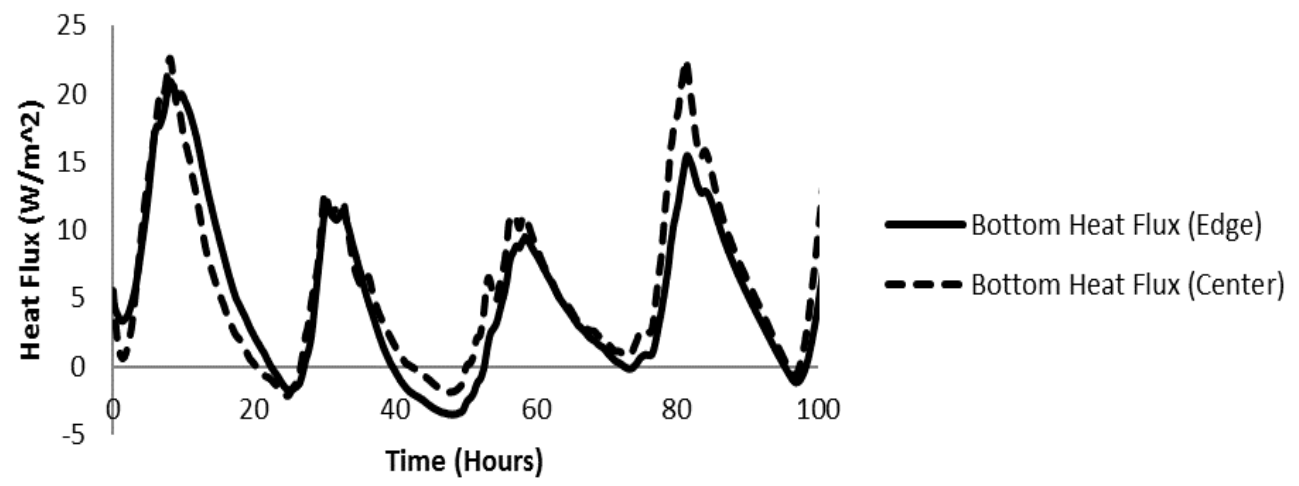

Fig. 8. Bottom heat flux at the center and edge point of thin concrete slab.

The heat flux at the bottom of slab for the first 100 hours of concrete casting represents the heat delivered to the bottom of the slab. The trend shows the heat flux is affected by weather fluctuation during day and night.

The temperature gradient at the $0.18 \mathrm{~m}$ slab is shown every day at 12 P.M. and 12 A.M. during one week after casting the concrete in Fig. 9 and Fig. 10, respectively. The temperature profiles are shown at a specific time of every day to see the temperature change days after casting the concrete. The results are presented in days after casting the thin slab concrete. 


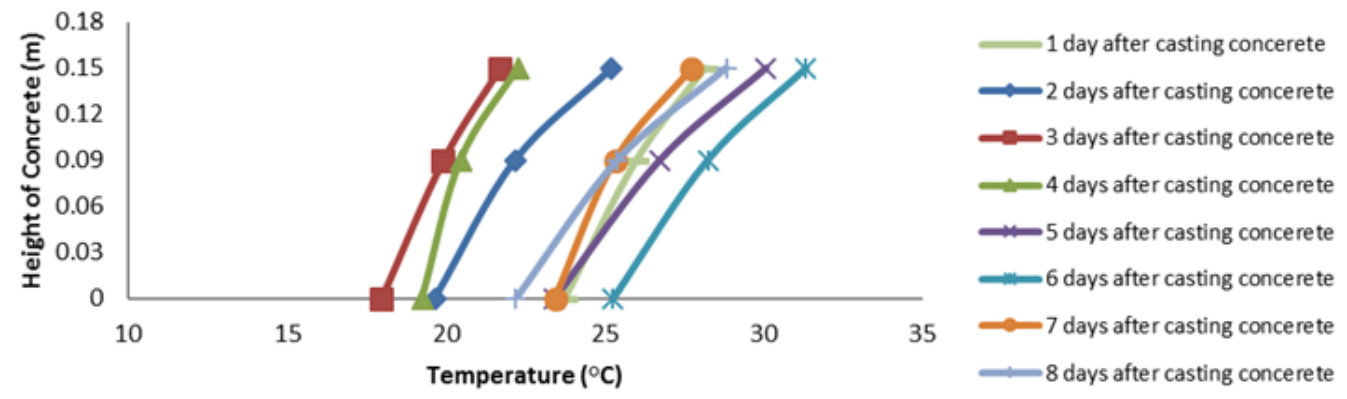

Fig. 9. Temperature gradient in height of thin slab at 12 P.M. of different days (Center).

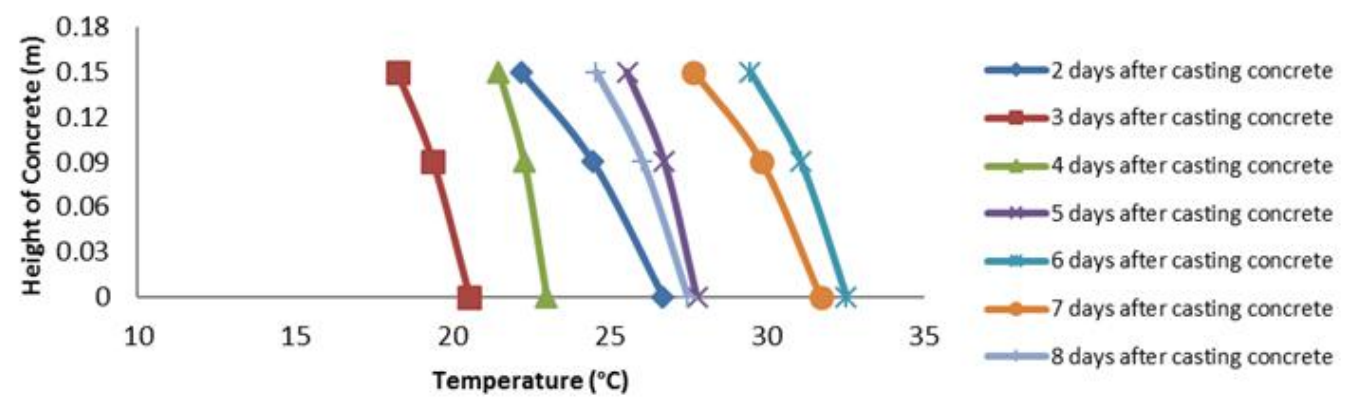

Fig. 10. Temperature gradient in height of thin slab at 12 A.M. of different days (Center).

Regarding the temperature at noon, the surface of the slab has a higher temperature than the bottom of the slab and this variation would be opposite at midnight. Temperature variation inside of the thin slab is nearly linear due to the thickness in comparison with the thicker mass concrete floor which has the nonlinear temperature gradient with a peak in the middle of slab. As a result, temperature rising in the thin slab is not a problem regarding temperature accumulation.

\section{Conclusion}

Summarizing, hydration heat in mass concrete structures because of the potential for thermal cracks and delayed ettringite formation should be considered for limstone blended cements. Limestone blended cement has a different heat of hydration in comparison with other ordinary portland cements. Based on the experiment, maximum temperature at the mass floor occurred at $42.94^{\circ} \mathrm{C}$ after 51.75 hours for the center point and $35.31^{\circ} \mathrm{C}\left(96.8^{\circ} \mathrm{F}\right)$ after 56.83 hours for the edge point. The heat is more accumulated at the center point because the center is surronded by the volume of concrete with low thermal conductivity. The vertical steel in the mass concrete floor transfers the heat of hydration to the top and bottom of slab because of higher thermal conductivity. Therefore, even the ground temperature is affected by hydration heat accumulation at the middle of slab.

In addition, temperature profile in the thin slab is linear and temperature profile in the mass concrete is nonlinear due to difference in thickness of slabs. The temperature profile in the thin slab is affected by the ambient temperature after casting the concrete. Also, the heat flux measurement and temperature profile in the thin slab illustrate that the hydration heat is not accumulated as much as mass floor.

\section{Acknowledgment}

The authors would like to appreciate LBI Company and Dr. Bruce Russell, director of Bert Cooper Laboratory at Oklahoma University for their great collaboration during the experiments. 


\section{References}

[1] www.wbcsdcement.org, Recycling Concrete, Executive summary. The cement sustainability initiative. World Business Council for Sustainable Development.

[2] Korea Concrete Institute. (2010). Thermal Crack Control of Mass Concrete, Concrete Practices Manual.

[3] Gurney, L., Bentz, D. P., Sato, T., \& Weiss, W. J. (2012). Using limestone to reduce set retardation in high volume fly ash mixtures: Improving constructability for sustainability. Transportation Research Record Journal of the Transportation Research Board, 2290, 139-146.

[4] Lawrence, A. M. (2009). A Finite Element Model for the Prediction of Thermal Stresses in Mass Concrete. PhD dissertation, University of Florida.

[5] Townsend, C. L. (1981). Control of Cracking in Mass Concrete Structures. Denver: A Water Resources Technical Publication Engineering Monograph No. 34, Dams Branch Division of Design, United States Department of the Interior Bureau Reclamation.

[6] Rahhal, V. F., Irassar, E. F., Trezza, M. A., \& Bonavetti, V. L. (2012). Calorimetric characterization of Portland limestone cement produced by intergrinding. Journal of Thermal Analysis and Calorimetry, 109(1), 153-161.

[7] Lothenbach, B., Le Saout, G., Gallucci, E., \& Scrivener, K. (2008). Influence of limestone on the hydration of Portland cements. Cement and Concrete Research, 38(6), 848-860.

[8] Shekarchizadeh, M., Tahersima, M., Hajibabaee, A., \& Layssi, H. (2008). Concrete mix proportions with ultra-high electrical resistivity. Proceedings of the International Conference on Durability of Building Materials and components. Istanbul, Turkey.

[9] Bentz, D. P., Irassar, E. F., Bucher, B., \& Weiss, W. J. (2010). Limestone fillers to conserve cement in low $\mathrm{w} / \mathrm{cm}$ concretes: An analysis based on powers' model. Concrete International.

[10] Cement and Concrete Terminology. (2005). ACI 318 Farmington Hills. American Concrete Institute.

[11] Ayotte, E., Massicotte, B., Houde, J., \& Gocevski, V. (1997). Modeling the thermal stress at early ages in a concrete monolith. ACI Materials Journal, 94(6), 577-587.

[12] Miao, B., Chaallal, O., Perraton, D., \& Aitcin, P. (1993). On-site early-age monitoring high-performance concrete columns. ACI Materials Journal, 90(5), 415-420.

[13] Hunt, J. G. (1971). A Laboratory Study of Early-Age Thermal Cracking of Concrete. Cement and Concrete Association.

[14] Ramezanianpour, A. A., Firoozmakan, S., Tahersima, M., \& Ebadi, T. (2010). Effects of Nano-Silica on Mechanical Properties of Mortars. Turkey:9th International Congress on Advances in Civil Engineering.

[15] Document provided from Holcim Inc. Ada, OK.

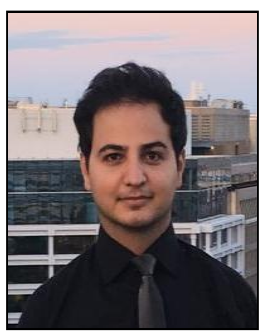

Mohammad Tahersima completed his PhD program in structural engineering from Oklahoma State University, 2017. He received his BSc degree in civil engineering from University of Tehran in 2008 and MSc in marine structural engineering from Iran University of Science and Technology, 2011. His research interest is about energy efficiency in the building, concrete repairs, concrete structural design, seismic and fatigue design of steel structures, and radiant floor system. 